\title{
Androgen receptor CAG polymorphism and sporadic and early-onset prostate cancer among Mexican men
}

\author{
Rocío Gómez ${ }^{1,6}$, Luisa Torres-Sánchez ${ }^{2,6}$, Rafael Camacho-Mejorado ${ }^{1}$, Ana I Burguete-García ${ }^{3}$, \\ Ruth Argelia Vázquez-Salas ${ }^{2}$, Gabriela A Martínez-Nava ${ }^{3,4}$, Carla Santana ${ }^{5}$ and Gino Noris ${ }^{5}$
}

A short CAG repeat length in the gene encoding for the androgen receptor (AR) has been associated with prostate cancer (PC) risk and aggressiveness. In Latino men, information on this association is scarce. Hence, the aim of this study was to evaluate this association in Mexican males. Using fragment analysis by capillary electrophoresis, we determined the number of CAG repeats-(CAG) $)_{n}$-in $A R$ gene from 158 incident PC cases and 326 age-matched healthy controls ( \pm 5 years), residing in Mexico City, Mexico. According to Gleason scale and age at diagnosis, cases were classified as high $(\geqslant 7)$ and low grade $(<7)$, as well as early onset ( $<60$ years) or late onset PC ( $\geqslant 60$ years). At diagnosis, $78 \%$ of cases were classified as high-grade and $26.6 \%$ as early onset. Men with sporadic (no family history of PC) and early-onset PC presented shorter CAG repeat length than controls $(18.6 \pm 2.2$ vs $19.5 \pm 2.5 ; P=0.02)$. Lower number of $C A G$ repeats $(C A G) \leqslant 19$ were associated with a greater risk for early-onset PC (odds ratio: $2.31 ; 95 \%$ confidence interval: $1.14-4.69$ ). CAG repeat length could increase the risk for sporadic and earlyonset PC. The best cutoff point for identifying at-risk subjects was (CAG) 19 . However, further studies are necessary to replicate our findings in subjects with a family history of PC and also to evaluate the association between CAG repeats length and disease progression.

Journal of Human Genetics (2016) 61, 781-786; doi:10.1038/jhg.2016.49; published online 19 May 2016

\section{INTRODUCTION}

In Mexico, prostate cancer (PC) is currently the first cause of morbidity (27.3 per 100000 inhabitants) and mortality (11.3 per 100000 inhabitants) among males. An estimated 30\% of PC cases are diagnosed in subjects prior to the age of 60 years. ${ }^{1}$ Interestingly, a high proportion of all cases, at the time of diagnosis, present a Gleason scale $\geqslant 7$ and are classified as high-grade or poorly differentiated cancer. ${ }^{2}$

Prior studies support that age, ethnicity, and a positive PC family history are important risk factors that contribute to the increase of PC development. ${ }^{3}$ Studies in twins reinforce that genes have a remarkable influence $(\sim 42 \%)$ on the development of PC. ${ }^{4}$ Given that prostate cell growth is hormone dependent, genes that participate in the synthesis pathways of steroid hormones have a critical role. ${ }^{5}$ Androgen receptor (AR) is a ligand-dependent transcriptional regulator codified on the $\mathrm{X}$ chromosome (q11-q12). This gene comprises eight exons in which different polymorphisms were found. As with other steroid receptors, AR contains a transactivation domain (located on the first exon) that encloses a trinucleotide motif $(\mathrm{CAG})_{\mathrm{n}}{ }^{6}$ This motif has been related to receptor activity, where a lower number of CAG repeats encode for a more active receptor and greater androgenic activity, even with the same amount of androgens. ${ }^{7-8}$
Preliminary studies suggest that a short CAG repeat length considerably increases risk for PC. ${ }^{9,10}$ Nonetheless, CAG repeat length associated with PC has been discrepant among populations, suggesting that average CAG repeat length exhibits an inter-ethnic variation. ${ }^{11}$ In this scenario, Afro-descendants and Caucasians present the shortest CAG repeat length and high PC incidence rates. ${ }^{3,12}$ In contrast, Asian and Hispanic populations have been related to largest CAG repeat length and consequently, at low risk for PC. ${ }^{9,10,12}$ However, in Hispanics, there are only two available studies, with conflicting results that examine CAG repeat length and related risk for PC. ${ }^{13,14}$ In a casecontrol study carried out in Hispanic residents from San Antonio, TX, USA, fewer than $(\mathrm{CAG})_{18}$ were associated with a threefold greater probability of PC. ${ }^{13}$ In contrast, another study in Hispanic residents from Los Angeles and Hawaii (USA), where the cutoff points employed were $<22$ or $<23$ CAG repeats, no association with PC risk or its extension was observed. ${ }^{14}$ In order to add to the limited findings among Hispanic populations, our study aimed to evaluate the association between CAG repeat length and the risk of PC in a population-based case-control study carried out with Mexican male residents in Mexico City.

\footnotetext{
${ }^{1}$ Departamento de Toxicología. Centro de Investigación y Estudios Avanzados del Instituto Politécnico Nacional (CINVESTAV), Mexico DF, México; ${ }^{2}$ Instituto Nacional de Salud Pública, Centro de Investigación en Salud Poblacional, Cuernavaca, México; ${ }^{3}$ Instituto Nacional de Salud Pública, Centro de Investigación en Enfermedades Infecciosas, Cuernavaca, México; ${ }^{4}$ Instituto Nacional de Rehabilitación 'Luis Guillermo Ibarra', Laboratorio de Líquido Sinovial, Mexico DF, México and ${ }^{5}$ Laboratorio BIMODI (Biología Molecular Diagnóstica), Santiago de Querétaro, México

${ }^{6}$ These authors contributed equally to this work.

Correspondence: Dr L Torres-Sánchez, Instituto Nacional de Salud Pública (INSP), Centro de Investigación en Salud Poblacional, Av Universidad 655, Col Sta María Ahuacatitlán, Cuernavaca, CP 62100 Morelos, México.

E-mail: Itorress@insp.mx

Received 8 February 2016; revised 4 April 2016; accepted 11 April 2016; published online 19 May 2016
} 


\section{MATERIALS AND METHODS}

\section{Study subject selection}

We analyzed the genetic data of unrelated 158 males with incident PC (cases) and 326 males without a diagnosis of PC (controls) ages 42-94 years, who resided in Mexico City, Mexico, and had no previous history of any other cancer type. Both groups comprised a random sample from a population-based case-control study (402 cases and 805 controls) performed from November 2011 to August 2014. ${ }^{15}$ Cases were recruited at three public and three social security hospitals in Mexico City. Controls were males matched by \pm 5 years of age with index cases, without a previous report of prostate-specific antigen $>4 \mathrm{ng} \mathrm{ml}^{-1}$, nor with malignant PC-related symptoms (that is, dysuria, hematuria, among others). Identification of controls was performed through the master sample framework utilized in National Health Surveys after the case was detected. In agreement with the 2005 National Census of Population and Housing, we selected 33 Basic Geostatistical Areas in Mexico City, each represented by 10 city blocks, which were visited from North to East in order to find a male possessing all of the criteria for consideration as a control. From each household, only one male was included in the study; if the next home belonged to same family, this household was not visited. Males who did not accept to participate in the study responded four questions about: educational level; marital status; birthplace; and length of time living in Mexico City. For the original study, the participation rate between cases and controls was $85.9 \%$ and $87.5 \%$, respectively.

Following the STREGA (STrengthening the REporting of Genetic Association Studies) statement, we included the study of genome control (GC) in order to support our findings and diminish false-positive results. ${ }^{16} \mathrm{GC}$ is a useful tool to depict the genetic architecture of complex populations. The GC was composed by 300 non-related individuals (150 females and 150 males) from a representative group of 1640 unrelated Mexican mestizo individuals from the Central Valley of Mexico previously described by our research group and only persons whose eight great-grandparents were born in Mexico were eligible. ${ }^{17}$

This population-based case-control study was conducted in accordance with the principles established by the Declaration of Helsinki and was approved by the Ethics Committee of the Mexican National Institute of Public Health (INSP; CI-980) and by each committee of the participating hospitals. Also, each GC signed an informed consent validated by the Ethics Committee of the Bimodi Research Unit. Through face-to-face interviews from each case and population control, we obtained information about sociodemographic characteristics, smoking habit, and familial history of PC in first-degree relatives. From each case, we obtained information on Gleason scale and histopathological diagnosis.

\section{Sample collection}

Peripheral venous blood was collected from all subjects in Vacutainer tubes containing EDTA (Becton Dickinson (BD), Franklin Lakes, NJ, USA). Peripheral blood mononuclear cells were obtained by Ficoll-hypaque density gradients (Hystopaque; Sigma Chemical Co., Sigma-Aldrich, St Louis, MO, USA), and genomic DNA was extracted from peripheral blood mononuclear cells using TRIzol reagent (Thermo Fisher Scientific, Suwanee, GA, USA). Sample concentration and purity was evaluated by Thermo Scientific NanoDrop 1000 Spectrophotometer (260/280), and DNA integrity was assessed by electrophoresis in $0.8 \%$ agarose gels.

\section{Polymorphism analysis}

PCR was performed with oligonucleotide primers previously reported by Westberg et al. ${ }^{18}$ Approximately $10 \mathrm{ng}$ of target DNA was amplified. The reaction was standardized at a $6-\mu \mathrm{l}$ total volume, containing $0.05 \mu \mathrm{M}$ primers, $1 \times$ reaction buffer with $\mathrm{NH}_{4} \mathrm{SO}_{2}, 20 \mathrm{~mm} \mathrm{MgCl}_{2}, 200 \mu \mathrm{M}$ of each nucleotide (Thermo Fisher Scientific), $1 \mathrm{~m}$ betaine (Sigma-Aldrich), and $1 \mathrm{U}$ Taq DNA polymerase (Thermo Fisher Scientific). The thermocycling procedure consisted of 30 cycles of denaturation at $94^{\circ} \mathrm{C}$ for $1 \mathrm{~min}$, annealing at $65^{\circ} \mathrm{C}$ for $1 \mathrm{~min}$, and extension at $72^{\circ} \mathrm{C}$ for $45 \mathrm{~s}$, followed by a final extension step of $10 \mathrm{~min}$ at $72{ }^{\circ} \mathrm{C}$. The resulting amplicons were analyzed by capillary electrophoresis on the ABI Prism 3130XL Genetic Analyzer employing GeneMapper ID ver. 3.2. software (Applied Biosystems, Carlsbad, CA, USA).

\section{Statistical analyses}

Selected characteristics between cases and controls were compared. Depending on the type of studied variable, Student's $t$-test, $\chi^{2}$-test or Fisher exact tests were utilized. Family history of PC in first-degree relatives was measured as 'yes' or 'no'. According to birth state, birthplace was categorized into six regions: Mexico City, South: Campeche, Chiapas, Guerrero, Oaxaca, Quintana Roo, and Yucatán; West-Central: Aguascalientes, Colima, Guanajuato, Jalisco, and Michoacán; East-Central: Hidalgo, State of Mexico, Morelos, Puebla, Querétaro, and Tlaxcala; North: Chihuahua, Coahuila, Durango, San Luis Potosí, Zacatecas, Baja California, Baja California Sur, Sinaloa, Sonora, Nayarit, Nuevo León, and Tamaulipas, and East: Veracruz and Tabasco.

Average CAG repeat length between cases and population controls were compared using the Student's $t$-test, and genetic differences between populations were evaluated by means of an analysis of molecular variance test. On the basis of a search of the previous literature, we categorized CAG repeat length using the following cutoffs: $\leqslant 18,19-25$, and $>25 ;<18$ vs $\geqslant 18$; $<19$ vs $\geqslant 19$; $<21$ vs $\geqslant 21$, and $<23$ vs $\geqslant 23$. To evaluate the association between CAG repeat length with cancer aggressiveness and age at diagnosis, we generated two different groups of cases. Based on Gleason scale ${ }^{19}$ at diagnosis, we considered as well-differentiated or low-risk, cancers in which the Gleason scale was $<7$; in contrast, poorly differentiated or high-risk cancers were those with a Gleason $\geqslant 7$. In relation to age at diagnosis, we categorized cases of $<60$ years of age as 'early-onset' vs $\geqslant 60$ years of age as 'elderly-onset'.

Allele and genotype frequencies in all studied groups were estimated using Arlequin v.3.1 software. ${ }^{20}$ Hardy-Weinberg expectation was calculated by applying Weir and Cockerham F Statistic (FISW\&C), using Genètix ver. 4.05.2 software. ${ }^{21}$

The crude and adjusted associations between AR CAG repeat length and PC risks were estimated using independent, unconditional logistic regression models for each case type. For each model, we employed AR CAG repeat length as a continuous variable and also independently we evaluated the different previously mentioned cutoff points. Age at interview was included as a continuous variable in bivariate and multivariable models. In addition to age, we evaluated, as a potential confounder, smoking history as well as birthplace. Due to the low prevalence of PC familial history among controls, we only report the association between AR CAG repeats and PC, including all individuals and males without a PC familial history. Cases in this latter analysis were considered as sporadic PC (no family history of PC). Sensitivity and specificity in the cutoffs were evaluated using Receiver Operating Characteristic (ROC) curves. All of the analyses were performed utilizing STATA ver. 14.0 statistical software.

\section{RESULTS}

At diagnosis, $78.2 \%$ of cases were classified as high-grade and poorly differentiated PC (Gleason $\geqslant 7$ ), while $26.6 \%$ were considered earlyonset prostate cancer (EO-PC; data not shown in tables). Regarding study design, we did not find significant differences in the average ages between cases and controls $(65.2 \pm 8.9$ vs $64.5 \pm 9.4$ years; $P=0.19)$. Compared with males born in Mexico City, those born in the EastCentral region had a nearly threefold (odds ratio, 2.70; 95\% CI, 1.644.46; $P=0.00$ ) increased risk of being cases. The prevalence of former smokers and familial history of PC was significantly higher among cases than controls (Table 1).

\section{Allele frequencies}

Allele frequency distribution of the CAG polymorphism is depicted in Table 2. The most frequent alleles in the three groups were 17, 18, 19, 20 and 21 (average 19.33 \pm 2.5 , range 10-29). Overall, the studied groups presented high-diversity patterns, exhibiting at least fifteen different alleles $(k)$ in cases group $(k=15)$, whereas the other groups presented $k=16$ (genome control, GC) and $k=17$ (population controls). Comparison among populations (cases, controls and GC) suggested that the groups were similar (genetic differences less than $1 \%, P \geqslant 0.25)$. The distribution of this polymorphism was in 
Table 1 Selected characteristics of the study population according to cases and controls

\begin{tabular}{|c|c|c|c|c|c|}
\hline \multirow[b]{2}{*}{ Characteristics } & Cases & Controls & \multirow[b]{2}{*}{$O R^{a}$} & \multirow[b]{2}{*}{$95 \% \mathrm{Cl}$} & \multirow[b]{2}{*}{ P-value } \\
\hline & $(n=158)$ & $(n=326)$ & & & \\
\hline \multicolumn{6}{|l|}{ Age (years) } \\
\hline Mean \pm s.d. & $65.2 \pm 8.9$ & $64.5 \pm 9.4$ & 1.0 & $0.99 ; 1.03$ & 0.19 \\
\hline Range & $43-87$ & $42-89$ & & & \\
\hline \multicolumn{6}{|l|}{ Birthplace $^{\mathrm{b}}(\%)$} \\
\hline Mexico City & $79(50.0)$ & $222(68.3)$ & 1.0 & - & \\
\hline South & $13(8.2)$ & $18(5.5)$ & 2.04 & $0.95 ; 4.39$ & 0.07 \\
\hline West-Central & $11(7.0)$ & $22(6.8)$ & 1.42 & $0.65 ; 3.08$ & 0.39 \\
\hline East-Central & $43(27.2)$ & $45(13.8)$ & 2.70 & $1.64 ; 4.46$ & 0.00 \\
\hline North & $4(2.5)$ & $7(2.1)$ & 1.60 & $0.46 ; 5.71$ & 0.34 \\
\hline East & $8(5.1)$ & $11(3.4)$ & 2.04 & $0.79 ; 5.26$ & 0.14 \\
\hline \multicolumn{6}{|l|}{ Marital status (\%) } \\
\hline $\begin{array}{l}\text { United }^{\mathrm{C}} \text { vs not } \\
\text { united }\end{array}$ & $118(74.68)$ & $258(79.1)$ & 0.77 & $0.50 ; 1.20$ & 0.28 \\
\hline \multicolumn{6}{|c|}{ Educational level (\%) } \\
\hline $\begin{array}{l}\leqslant \text { Elementary } \\
\text { school }\end{array}$ & $75(47.5)$ & $145(44.5)$ & 1.0 & - & \\
\hline $\begin{array}{l}\text { Junior-High } \\
\text { school }\end{array}$ & $24(15.2)$ & $79(24.2)$ & 0.60 & $0.35 ; 1.04$ & 0.09 \\
\hline High school & $30(19.0)$ & $56(17.2)$ & 1.07 & $0.63 ; 1.83$ & 0.76 \\
\hline $\begin{array}{l}\text { University or } \\
\text { more }\end{array}$ & $29(18.4)$ & $46(14.1)$ & 1.26 & $0.73 ; 2.18$ & 0.35 \\
\hline \multicolumn{6}{|c|}{ Smoking status ${ }^{\mathrm{d}}(\%)$} \\
\hline Never smoked & $51(32.3)$ & $112(34.4)$ & 1.0 & - & \\
\hline \multicolumn{6}{|l|}{ Former smoker } \\
\hline$>15 y$ & $34(21.5)$ & $54(16.6)$ & 1.36 & $0.78 ; 2.35$ & 0.27 \\
\hline & $36(22.8)$ & $47(14.4)$ & 1.70 & $0.98 ; 2.93$ & 0.06 \\
\hline Current smoker & $37(23.4)$ & $113(34.7)$ & 0.56 & $0.44 ; 1.20$ & 0.21 \\
\hline \multicolumn{6}{|c|}{ Familial history of PC (\%) } \\
\hline Yes vs No & $18(11.4)$ & $4(1.2)$ & 10.35 & $3.44 ; 31.14$ & 0.00 \\
\hline \multicolumn{6}{|c|}{$\begin{array}{l}\text { Abbreviations: Cl, confidence interval; PC, prostate cancer. } \\
\text { aOdds ratio (OR) adjusted by age at interview. } \\
\text { 'Birthplace: Mexico City. South: Campeche, Chiapas, Guerrero, Oaxaca, Quintana Roo, and } \\
\text { Yucatán; West-Central: Aguascalientes, Colima, Guanajuato, Jalisco, and Michoacán; East- } \\
\text { Central: Hidalgo, State of Mexico, Morelos, Puebla, Querétaro, and Tlaxcala; North: Chihuahua, } \\
\text { Coahuila, Durango, San Luis Potosí, Zacatecas, Baja California, Baja California Sur, Sinaloa, } \\
\text { Sonora, Nayarit, Nuevo León, and Tamaulipas, and East: Veracruz and Tabasco. } \\
\text { cUnited: common law marriage and marriage. } \\
\text { dSmoking condition five years before interview. }\end{array}$} \\
\hline
\end{tabular}

agreement with Hardy-Weinberg equilibrium $(P>0.05)$, which was obtained from women in the GC.

Compared with population controls, PC cases in general $(19.5 \pm 2.5$ vs $19.0 \pm 2.6 ; P=0.06)$ and $P C$ classified as poorly differentiated at time of diagnosis $(19.5 \pm 2.5$ vs $18.9 \pm 2.5 ; P=0.06)$ had a marginally lower average of repeats. In contrast, EO-PC cases $(18.6 \pm 2.2 ; P=0.02)$ presented a significantly lower average of CAG repeats (Figures la-c). Birthplace was associated with the number of CAG repeats. Males born in the South region presented on average a greater number of triplets than those born in Mexico City $(20.7 \pm 3.5 ; P=0.003)$; in contrast, subjects born in the North region had a marginally lower average of CAG repeats $(17.8 \pm 2.8 ; P=0.07)$. The average number of CAG repeats length among those with a familial history of PC was lower $(18.7 \pm 3.9$; $P=0.11$ ), but not statistically significant (Table 3 ).
Table 2 Allele frequencies and descriptive statistics parameters regarding the locus studied in cases, controls and genome control

\begin{tabular}{|c|c|c|c|c|}
\hline \multirow[b]{3}{*}{ Allele/N } & \multirow[b]{2}{*}{ Cases } & \multirow[b]{2}{*}{ Controls } & \multicolumn{2}{|c|}{ Genome Control } \\
\hline & & & \multirow{2}{*}{$\begin{array}{c}\text { Men } \\
(n=150)\end{array}$} & \multirow{2}{*}{$\begin{array}{c}\text { Women } \\
(\mathrm{n}=150)\end{array}$} \\
\hline & $(n=158)$ & $(n=314)$ & & \\
\hline 10 & - & 0.003 & - & 0.003 \\
\hline 12 & 0.006 & 0.003 & 0.007 & - \\
\hline 13 & 0.025 & 0.003 & - & 0.017 \\
\hline 14 & 0.013 & 0.006 & 0.013 & 0.030 \\
\hline 15 & 0.019 & 0.019 & 0.033 & 0.053 \\
\hline 16 & 0.051 & 0.041 & 0.020 & 0.063 \\
\hline 17 & 0.133 & 0.131 & 0.233 & 0.147 \\
\hline 18 & 0.190 & 0.147 & 0.147 & 0.143 \\
\hline 19 & 0.165 & 0.194 & 0.133 & 0.127 \\
\hline 20 & 0.139 & 0.147 & 0.113 & 0.140 \\
\hline 21 & 0.120 & 0.121 & 0.120 & 0.103 \\
\hline 22 & 0.063 & 0.076 & 0.067 & 0.053 \\
\hline 23 & 0.025 & 0.054 & 0.040 & 0.057 \\
\hline 24 & 0.006 & 0.019 & 0.033 & 0.027 \\
\hline 25 & 0.038 & 0.022 & 0.007 & 0.023 \\
\hline 26 & 0.006 & 0.006 & 0.013 & 0.010 \\
\hline 27 & - & - & 0.013 & 0.003 \\
\hline 29 & - & 0.006 & 0.007 & - \\
\hline \multicolumn{5}{|c|}{ Descriptive Statistics } \\
\hline k & 15 & 17 & 16 & 16 \\
\hline Ho & 0.000 & 0.000 & 0.000 & 0.893 \\
\hline $\mathrm{He}$ & 0.875 & 0.876 & 0.870 & 0.896 \\
\hline HWE $(P)$ & $\leqslant 0.0001$ & $\leqslant 0.0001$ & $\leqslant 0.0001$ & 0.932 \\
\hline$F_{I S}$ & 1 & 1 & 1 & 0.003 \\
\hline
\end{tabular}

\section{PC and CAG repeat length}

In order to assess a linear association between CAG repeat length and PC, we carried out a model employing CAG repeat length as a continuous variable. Overall, for each increase in number of CAG repeats, we observed a reduction in the risk of PC. However, this was only statistically significant for EO-PC (odds ratio, 0.83 ; 95\% CI, 0.71 ; $0.97 ; P=0.02$ ). For all $\mathrm{PC}$ and for Gleason $\geqslant 7$, the reduction in the risk associated with the increase of copies was marginally significant (Table 4). On evaluating different cutoff points, solely the cutoff point in 19 repeated sequences $(\mathrm{CAG})_{19}$ exhibited the best combination of sensitivity (0.48) and specificity (0.70) for identifying the risk condition (data not shown). Lower number of (CAG) 19 repeats was significantly associated with a two-fold greater risk of EO-PC (odds ratio, $2.31 ; 95 \% \mathrm{CI}, 1.14 ; 4.69 ; P=0.02$ ) and a marginal increase in the risk of PC in general or for poorly differentiated cancer (Gleason $\geqslant 7$ ). With others cutoff points, although associated with a greater risk of PC in general, the associations were not statistically significant. In subjects without a familial history of PC, the association observed with EO-PC remained statistically significant and of the same magnitude (Table 4).

\section{DISCUSSION}

In agreement with previous reports, this study suggests that in Mexican men, a fewer number of CAG repeats in the gene encoding for the AR might be associated with a greater risk of sporadic and EOPC. The cutoff point that best identified subjects at risk for presenting 

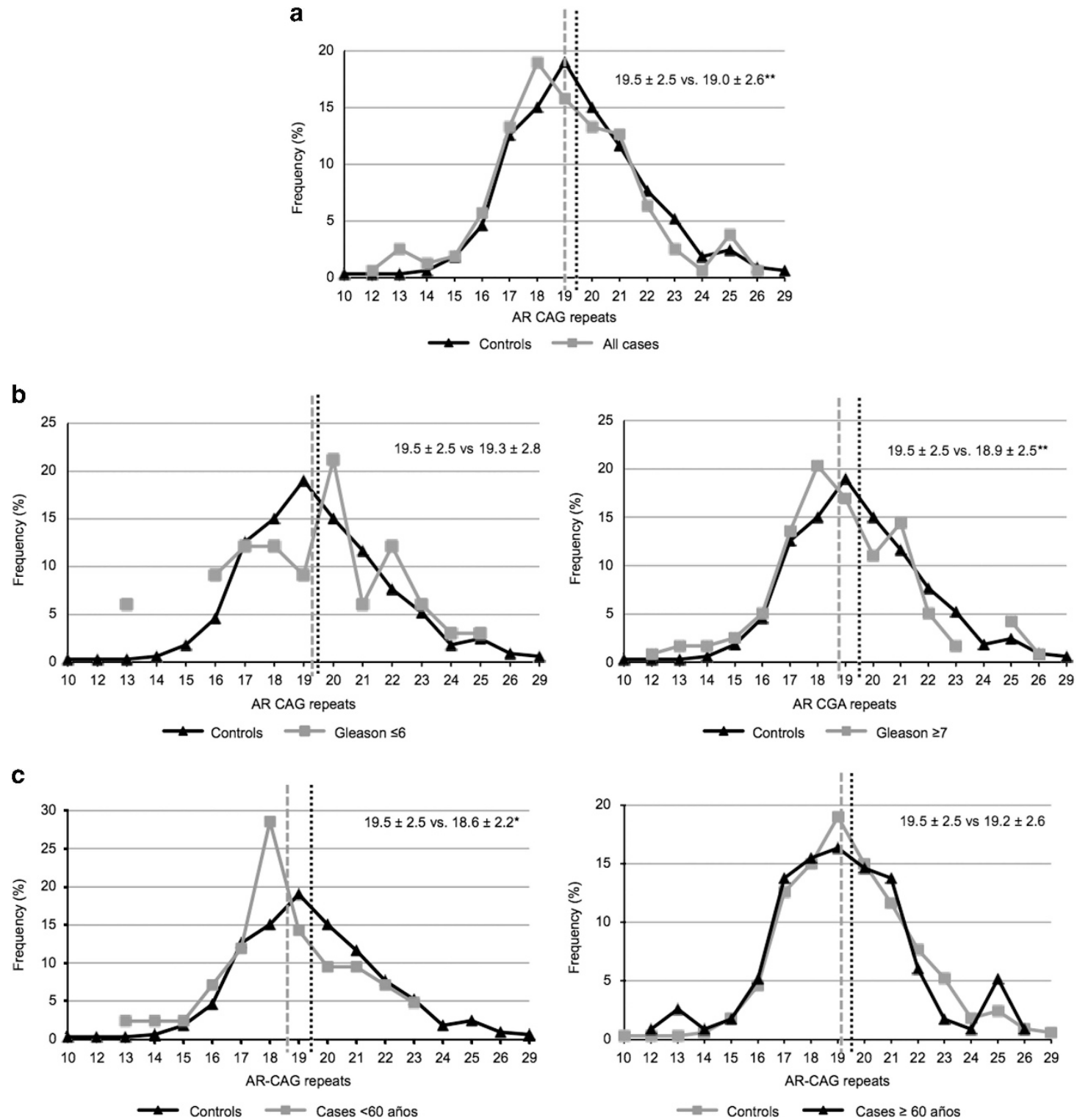

Figure 1 Distribution of CAG repeat length in $A R$ gene, according to prostate cancer cases and controls. *Student's $t$-test, $P$-value for cases and controls $<0.05$; **Student's $t$-test, $P$-value for cases and controls $=0.06$.

this neoplasm was $\leqslant(\mathrm{CAG})_{19}$ repeat length. Likewise, these results suggest that the differential distribution of CAG repeat length across regions of Mexico could be a potential explanation for the regional distribution of PC across the country observed in the Histopathological National Register of Cancer from 1993 to 2002;22 in that study most of the prostate tumors were reported in Mexico City, followed by the northern, center and southern states of the country.

The results of this study are consistent with the majority of studies conducted in Afro-descendent, Caucasian and Asiatic populations, ${ }^{9,10}$ especially with a study carried out in Sweden where they found that short CAG repeats in the $A R$ gene correlate with young age at diagnosis of sporadic PC. ${ }^{23}$ Moreover, our results are in agreement with the two studies that have evaluated this association in Hispanic population. The study carried out in Hispanic residents of San Antonio, Texas, USA, reported that a CAG repeat length $\leqslant 18$ was associated with a three-fold greater risk for PC. ${ }^{13}$ This association was stronger when the analysis was restricted to cases of PC aged $<65$ years (odds ratio, 3.03; 95\% CI, 1.27-7.26). The results of the multiethnic cohort in Hawaii and Los Angeles, CA, USA, were consistent with our results, due to that we did not find a significant association when similar cutoff points to those utilized by the abovementioned authors ( $<22$ and $<23$ CAG repeats). ${ }^{14}$

The main proposed biological mechanism for the association between shorter CAG repeat length and PC risk is the increased receptor activity; however, several studies suggest that CAG repeat length may increase PC risk-mediating androgen-induced TMPRSS2 and ERG proximity. ${ }^{24}$ About a half of human PCs display a TMPRSS2-ERG gene fusion, which is one of the most common genomic aberrations in PC. This gene fusion is related with a poor PC prognosis. $^{25}$

Comparison between included and not included subjects in this analysis (Supplementary Table S1) showed that a higher proportion of included controls did not have familial history of PC (1.2 vs 3.5\%). The external validity of our results is limited to subjects without 
Table 3 Androgen receptor (AR) CAG repeats according to selected characteristics of the study population

\begin{tabular}{|c|c|c|c|}
\hline Characteristics & $N=484$ & CAG repeats; mean \pm s.d. & $\mathrm{P}$-value \\
\hline \multicolumn{4}{|l|}{ Birthplace $^{\mathrm{b}}$} \\
\hline Mexico City & 301 & $19.3 \pm 2.4$ & \\
\hline South & 31 & $20.7 \pm 3.5$ & 0.003 \\
\hline West-Central & 33 & $19.3 \pm 2.4$ & 0.86 \\
\hline East-Central & 88 & $19.2 \pm 2.6$ & 0.91 \\
\hline North & 11 & $17.8 \pm 2.8$ & 0.07 \\
\hline East & 19 & $19.6 \pm 2.2$ & 0.55 \\
\hline \multicolumn{4}{|l|}{ Civil status } \\
\hline United $^{\mathrm{C}}$ vs Not united & 376 & $19.3 \pm 2.5$ & 0.73 \\
\hline \multicolumn{4}{|l|}{ Educational level } \\
\hline Elementary school & 220 & $19.2 \pm 2.4$ & \\
\hline Junior-High school & 103 & $19.6 \pm 2.6$ & 0.15 \\
\hline High school & 86 & $19.4 \pm 2.5$ & 0.64 \\
\hline University or more & 75 & $19.2 \pm 2.9$ & 0.89 \\
\hline \multicolumn{4}{|l|}{ Smoking status ${ }^{d}$} \\
\hline Never smoked & 163 & $19.5 \pm 2.7$ & \\
\hline \multicolumn{4}{|l|}{ Former smoker } \\
\hline$>15$ years & 88 & $19.7 \pm 2.7$ & 0.15 \\
\hline$\leqslant 15$ years & 83 & $19.1 \pm 2.3$ & \\
\hline Current smoker & 150 & $19.1 \pm 2.4$ & \\
\hline \multicolumn{4}{|c|}{ Familial history of prostate cancer $(P C)(\%)$} \\
\hline No & 462 & $19.3 \pm 2.5$ & \\
\hline Yes & 22 & $18.7 \pm 3.9$ & 0.11 \\
\hline
\end{tabular}

aAnalysis of variance and Student's $t$-test.

bBirthplace: Mexico City. South: Campeche, Chiapas, Guerrero, Oaxaca, Quintana Roo, and Yucatán; West-Central: Aguascalientes, Colima, Guanajuato, Jalisco, and Michoacán; EastCentral: Hidalgo, State of Mexico, Morelos, Puebla, Querétaro, and Tlaxcala. North: Chihuahua, Coahuila, Durango, San Luis Potosí, Zacatecas, Baja California, Baja California Sur, Sinaloa, Sonora, Nayarit, Nuevo León, and Tamaulipas, and East: Veracruz and Tabasco.

CUnited: Common law marriage and marriage.

dSmoking condition five years before interview. familial history of PC. Therefore, we were not able to establish if the magnitude of this association could be similar among subjects with a family history of PC. Given that we did not find differences related to CAG repeat length between the population controls and GC, the probability of our results to be a consequence of selection bias is low. In addition, although all analysis were adjusted for place of birth, as a proxy measure for genetic ancestry, there is a possibility of having residual confounding. Some evidence suggests that body mass index is related with the risk for PC and the number of CAG repeats. However, we did not include body mass index in our analysis owing to body mass index information that we had was at the time of the interview and it did not adequately represent the subjects' body composition, mainly among cases, which can be affected by the disease. Likewise, we discarded the possibility that the results observed were the consequence of a differential measurement error in the determination of the number of CAG copies, because the person charged with carrying out this determination was unaware of case or control condition. If a measurement error was present, it would be of the non-differential type and would impact the results toward underestimation of the association.

To our knowledge this is the first study that examines the role of the lower number of CAG repeats as a risk factor for PC in Mexican males. In addition, findings from this study may help inform the establishment of cutoff points for determining potential PC risk in this population related to $(\mathrm{CAG})_{19}$. A previous small study (68 PC cases vs 48 healthy men) carried out in Mexican men suggests an association between shorter CAG repeat length and latter age at PC diagnosis; ${ }^{26}$ however, some methodological limitations (selection of the study subjects and measurement of CAG repeat length) limit the validity and interpretation of these results. Finally, longitudinal studies are needed to determine and evaluate CAG cutoff points as potential risk factors for developing PC, as well as for disease progression. A high proportion of cancers respond to androgen ablation; however, part of these cancers become resistant to treatment and it is not impossible

Table 4 Androgen receptor (AR) CAG repeats length and its association with prostate cancer (PC) using different cutoff points

\begin{tabular}{|c|c|c|c|c|c|c|c|c|c|c|c|c|c|c|}
\hline \multirow[b]{3}{*}{ Characteristics } & \multicolumn{2}{|c|}{ CAG continuous } & \multicolumn{12}{|c|}{ CAG categories } \\
\hline & \multirow[b]{2}{*}{$O R^{a, b}$} & \multirow[b]{2}{*}{$95 \% \mathrm{Cl}$} & \multicolumn{3}{|c|}{$<18 v s \geqslant 18$} & \multicolumn{3}{|c|}{$<19$ vs $\geqslant 19$} & \multicolumn{3}{|c|}{$<21$ vs $\geqslant 21$} & \multicolumn{3}{|c|}{$<23 v s \geqslant 23$} \\
\hline & & & $\mathrm{N}$ & $O R^{b}$ & $95 \% \mathrm{Cl}$ & $\mathrm{N}$ & $O R^{\mathrm{b}}$ & $95 \% \mathrm{Cl}$ & $\mathrm{N}$ & $O R^{\mathrm{b}}$ & $95 \% \mathrm{Cl}$ & $\mathrm{N}$ & $O R^{\mathrm{b}}$ & $95 \% \mathrm{Cl}$ \\
\hline \multicolumn{15}{|l|}{ All } \\
\hline Controls $(n=326)$ & - & - & 67 & - & - & 116 & - & - & 227 & - & - & 290 & - & - \\
\hline \multicolumn{15}{|l|}{ Cases } \\
\hline All $(n=158)$ & 0.93 & $0.8 ; 1.00$ & 40 & 1.30 & $0.83 ; 2.03$ & 70 & 1.44 & $0.98 ; 2.11$ & 116 & 1.20 & $0.78 ; 1.83$ & 146 & 1.51 & $0.76 ; 2.98$ \\
\hline Gleason $<7(n=33)$ & 0.97 & $0.84 ; 1.12$ & 9 & 1.45 & $0.64 ; 3.28$ & 13 & 1.18 & $0.56 ; 2.45$ & 23 & 1.00 & $0.46 ; 2.19$ & 29 & 0.9 & $0.30 ; 2.71$ \\
\hline Gleason $\geqslant 7(n=118)$ & 0.92 & $0.84 ; 1.00$ & 30 & 1.30 & $0.80 ; 2.14$ & 54 & 1.53 & $1.00 ; 2.34$ & 87 & 1.22 & $0.76 ; 1.96$ & 110 & 1.71 & $0.77 ; 3.80$ \\
\hline Cases $<60$ years $(n=42)$ & 0.83 & $0.71 ; 0.97^{c}$ & 11 & 1.77 & $0.77 ; 4.04$ & 23 & 2.31 & $1.14 ; 4.69^{c}$ & 33 & 1.75 & $0.76 ; 4.02$ & 40 & 2.45 & $0.53 ; 11.39$ \\
\hline Cases $\geqslant 60$ years $(n=116)$ & 0.96 & $0.89 ; 1.05$ & 29 & 1.18 & $0.71 ; 1.97$ & 47 & 1.16 & $0.74 ; 1.82$ & 83 & 1.01 & $0.63 ; 1.64$ & 106 & 1.25 & $0.60 ; 2.66$ \\
\hline \multicolumn{15}{|l|}{ No familial history of prostate cancer } \\
\hline Controls $(n=322)$ & - & - & 65 & - & - & 114 & - & - & 225 & - & - & 288 & - & - \\
\hline \multicolumn{15}{|l|}{ Cases } \\
\hline All $(n=140)$ & 0.95 & $0.88 ; 1.03$ & 32 & 1.15 & $0.71 ; 1.87$ & 58 & 1.29 & $0.86 ; 1.93$ & 102 & 1.50 & $0.74 ; 1.79$ & 129 & 1.38 & $0.68 ; 2.82$ \\
\hline Gleason $<7(n=30)$ & 1.02 & $0.88 ; 1.19$ & 7 & 1.2 & $0.49 ; 2.93$ & 10 & 0.91 & $0.41 ; 2.01$ & 20 & 0.86 & $0.39 ; 1.91$ & 26 & 0.78 & $0.25 ; 2.33$ \\
\hline Gleason $\geqslant 7(n=103)$ & 0.93 & $0.85 ; 1.02$ & 24 & 1.18 & $0.69 ; 2.02$ & 45 & 1.41 & $0.90 ; 2.22$ & 76 & 1.21 & $0.73 ; 2.00$ & 96 & 1.63 & $0.70 ; 3.79$ \\
\hline Cases $<60$ years $(n=40)$ & 0.84 & $0.72 ; 0.99^{c}$ & 10 & 1.62 & $0.69 ; 3.80$ & 21 & 2.31 & $1.13 ; 4.69^{c}$ & 31 & 1.56 & $0.67 ; 3.63$ & 38 & 2.03 & $0.43 ; 9.57$ \\
\hline Cases $\geqslant 60$ years $(n=100)$ & 0.99 & $0.91 ; 1.09$ & 22 & 1.00 & $0.57 ; 1.76$ & 37 & 0.99 & $0.61 ; 1.61$ & 71 & 0.97 & $0.58 ; 1.61$ & 91 & 1.15 & $0.52 ; 2.54$ \\
\hline
\end{tabular}

Abbreviations: $\mathrm{Cl}$, confidence interval; OR, odds ratio.

aPer each increase of one CAG repeat.

${ }^{b}$ All adjusted by age and birthplace.

${ }^{\mathrm{c}} P$-value $<0.05$. 
to think that this lack of response could be associated with the presence of this polymorphism. Finally, it is crucial to establish a National Cancer Registry in Mexico, which could provide a comprehensive repository of data to help guide related research and practice guidelines to reduce the risk of PC morbidity and mortality.

\section{CONFLICT OF INTEREST}

The authors declare no conflict of interest.

\section{ACKNOWLEDGEMENTS}

This study was supported by CONACyT grant number 140482 (to LT-S). We are grateful for the contribution of Arianna Ventura-Bahena, and of Ms Nicol Ventura-Bahena, who participated in the conformation of the samples bank and the coding and entering of the information, respectively. Likewise, we are grateful to each of the participating hospitals: General Hospital of Mexico (SSA), National Cancer Institute (SSA), Salvador Zubirán National Institute of Medical and Nutrition Sciences (SSA), and the Centro Médico Nacional Siglo XXI Oncology Hospital (IMSS), the Dr Carlos McGregor Sánchez Navarro Regional General Hospital No.1 (IMSS) and the Adolfo López Mateos Regional Hospital (ISSSTE). We also thank Laboratorio de Genómica, Proteómica y Metabolómica from LaNSE-Cinvestav for helping with the genotyping processes.

1 Ferlay, J., Soerjomataram, I., Ervik, M., Dikshit, R., Eser, S., Mathers, C. et al. GLOBOCAN 2012 v1.0, Cancer Incidence and Mortality Worldwide: IARC CancerBase No. 11 Internet. Lyon, France (2013): International Agency for Research on Cancer. http://globocan.iarc.fr. Accessed 13 March 2016.

2 Gomez-Guerra, L. S., Martinez-Fierro, M. L., Alcantara-Aragon, V., Ortiz-Lopez, R., Martinez-Villarreal, R. T., Morales-Rodriguez, I. B. et al. Population based prostate cancer screening in north Mexico reveals a high prevalence of aggressive tumors in detected cases. BMC Cancer 9, 91-96 (2009).

3 Grönberg, H. Prostate cancer epidemiology. Lancet 361, 859-864 (2003).

4 Lichtenstein, P., Holm, N. V., Verkasalo, P. K., Iliadou, A., Kaprio, J., Koskenvuo, M. et al. Environmental and heritable factors in the causation of cancer- analyses of cohorts of twins from Sweden, Denmark, and Finland. N. Engl. J. Med. 343, 78-85 (2000).

5 Bosland, M. C. \& Mahmoud, A. M. Hormones and prostate carcinogenesis: androgens and estrogens. J. Carcinog. 10, 33 (2011).

6 Koochekpour, S. Androgen receptor signaling and mutations in prostate cancer. Asian J. Androl. 12, 639-657 (2010).

7 Buchanan, G., Yang, M., Cheong, A., Harris, J. M., Irvine, R. A., Lambert, P. F. et al. Structural and functional consequences of glutamine tract variation in the androgen receptor. Hum. Mol. Genet. 13, 1677-1692 (2004).

8 Beilin, J., Ball, E. M., Favaloro, J. M. \& Zajac, J. D. Effect of the androgen receptor CAG repeat polymorphism on transcriptional activity: specificity in prostate and non-prostate cell lines. J. Mol. Endocrinol. 25, 85-96 (2000).
9 Gu, M., Dong, X., Zhang, X. \& Niu, W. The CAG repeat polymorphism of androgen receptor gene and prostate cancer: a meta-analysis. Mol. Biol. Rep. 39, 2615-2624 (2012)

10 Sun, J. H. \& Lee, S. A. Association between CAG repeat polymorphisms and the risk of prostate cancer: a meta-analysis by race, study design and the number of (CAG)n repeat polymorphisms. Int. J. Mol. Med. 32, 1195-1203 (2013).

11 Williams, H. \& Powell, I. J. Epidemiology, pathology, and genetics of prostate cancer among African Americans compared with other ethnicities. Methods Mol. Biol. 472, 439-453 (2009).

12 Ackerman, C. M., Lowe, L. P., Lee, H., Hayes, M. G., Dyer, A. R., Metzger, B. E. et al. Ethnic variation in allele distribution of the androgen receptor (AR) (CAG)n repeat. J. Androl. 33, 210-215 (2012).

13 Balic, I., Graham, S. T., Troyer, D. A., Higgins, B. A., Pollock, B. H., Johnson-Pais, T. L. et al. Androgen receptor length polymorphism associated with prostate cancer risk in Hispanic men. J. Urol. 168, 2245-2248 (2002).

14 Freedman, M. L., Pearce, C. L., Penney, K. L., Hirschhorn, J. N., Kolonel, L. N., Henderson, B. E. et al. Systematic evaluation of genetic variation at the androgen receptor locus and risk of prostate cancer in a multiethnic cohort study. Am. J. Hum. Genet. 76, 82-90 (2005).

15 Vázquez-Salas, R. A., Torres-Sánchez, L López-Carrillo, L., Romero-Martínez, M. Manzanilla-García, H. A., Cruz-Ortíz, C. H. et al. History of gonorrhea and prostate cancer in a population-based case-control study in Mexico. Cancer Epidemiol. 40, 95-101 (2016).

16 Silviu-Alin, B., Devlin, B. \& Roeder, K. The power of genomic control. Am. J. Hum. Genet. 66, 1933-1944 (2000).

17 Noris, G., Santana, C., Meraz-Ríos, M. A., de Lourdes Muñoz, M., Majluf-Cruz, A., Magaña, J. J. et al. Mexican mestizo population sub-structure: effects on genetic and forensic statistical parameters. Mol. Biol. Rep. 39, 10139-10156 (2012).

18 Westberg, L., Henningsson, S., Landén, M., Annerbrink, K., Melke, J., Nilsson, S. et al. Influence of androgen receptor repeat polymorphisms on personality traits in men. J. Psychiatry Neurosci. 34, 205-213 (2009).

19 Humphrey, P. A. Gleason grading and prognostic factors in carcinoma of the prostate. Mod. Pathol. 17, 292-306 (2004).

20 Excoffier, L., Laval, G. \& Schneider, S. Arlequin ver. 3.1: An integrated software package for population genetics data analysis. Evol. Bioinform. Online 1, 47-50 (2005).

21 Belkhir, L. C., Raufaste, N. \& Bonhomme, F. in GENETIX 4.05 Logiciel Sous Windows TM Pour la Génétique des Populations. (eds Laboratoire Génome P) Interactions, CNRS UMR 5171 (Université de Montpellier II, Montpellier, 1996-2004).

22 Meneses-García, A., Ruiz-Godoy, L. M., Beltrán-Ortega, A., Sánchez-Cervantes, F., Tapia-Conyer, R. \& Mohar, A. Principales neoplasias malignas en México y su distribución geográfica (1993-2002). Rev. Inv. Clin. 64, 322-329 (2012).

23 Bratt, O., Borg, A., Kristoffersson, U., Lundgren, R., Zhang, Q. X. \& Olsson, H. CAG repeat length in the androgen receptor gene is related to age at diagnosis of prostate cancer and response to endocrine therapy, but not to prostate cancer risk. Br. J. Cancer 81, 672-676 (1999).

24 Mao, X., Li., J., Xu, X., Boyd, L. K., He, W., Stankiewicz, E. et al. Involvement of different mechanisms for the association of CAG repeat length polymorphism in androgen receptor gene with prostate cancer. Am. J. Cancer Res. 4, 886-896 (2014).

25 Yoshimoto, M., Joshua, A. M., Cunha, I. W., Coudry, R. A., Fonseca, F. P., Ludkovski, 0 . et al. Absence of TMPRSS2:ERG fusions and PTEN losses in prostate cancer is associated with a favorable outcome. Mod. Pathol. 21, 1451-1460 (2008).

26 Patiño-García, B., Arroyo, C., Rangel-Villalobos, H., Soto-Vega, E., Velarde-Félix, J. S., Gabilondo, F. et al. Association between polymorphisms of the androgen and vitamin D receptor genes with prostate cancer risk in a Mexican population. Rev. Invest. Clin. 59, 25-31 (2007).

Supplementary Information accompanies the paper on Journal of Human Genetics website (http://www.nature.com/jhg) 